\title{
The startup balancing act: Hiring the right talent
}

\section{Money versus management is the first hurdle your business plan must overcome.}

\section{Simon Moroney}

For any company that wants to be competitive in the global biotechnology industry, raising venture capital is an absolute necessity. For the rapidly emerging European biotechnology sector, understanding the rules of how to do this is especially important because, until recently, access to venture capital money was relatively limited when compared to the US.

To the surprise of many budding entrepreneurs in both Europe and the US, the initial stumbling block to securing $\mathrm{VC}$ funding is most often not a question of how much money is being exchanged for what percentage of equity in the company. Rather, it is how the $\mathrm{VC}$ envisions a startup's management versus what the founder sees as the talent needed to make the company grow.

Negotiating money versus management is a critical step: Following the VC strategy may secure your company the initial funding, but doom it to failure by saddling it with management that doesn't understand what is truly unique about it. The flip side is that while you can assemble a "dream team" for your company in your mind, without the finances to pay them you will never have the opportunity to prove that your idea will work. Either way, it is a false step at this point and you are likely to see your dream go up in smoke.

\section{Why venture capital?}

As anyone acquainted with the burn rate of a biotechnology company knows, as an industry, biotechnology is particularly dependent on access to substantial levels of capital in order to succeed. In fact, failure to raise sufficient capital early in the company's development is most often a contributing cause to its failure. The reason for this is simple: If the company runs out of money early on, management must focus on raising additional capital before it really has a lot to show in terms of measurable progress-granted patents, collaborations with major pharmaceutical companies, or products entering into clinical trials.

Given this need for vast sums of upfront money, many would-be entrepreneurs fear

Simon Moroney is president \& CEO of MorphoSys GmbH, Am Klopferspitz 19, 82152 Martinsried/Munich, Germany (moroney@morphosys.de). that venture capital financing will result in loss of control over their business through loss of equity. What they fail to appreciate is that if they choose their VC appropriately, they are receiving more than just money in this exchange. The VC company also provides value-both direct and perceived. Beyond cash, the most valuable asset the $\mathrm{VC}$ provides is the experience it has gained through its involvement in other similar enterprises.

This experience can be invaluable to founders, especially when it comes to advising on what strategy the company should pursue. For example, entrepreneurs coming from an academic background often lack an understanding of the market for the product or technology that the new company will produce. Here, the venture capitalist, being a close observer of the industry, can be of help.

The perceived value of the venture capital company is often hard for new bioentrepreneurs to see at this stage. However, as your company begins to recruit employees, seek additional funding, or attract media attention, most often your alignment with a VC company that is well respected will serve as an implicit validation of your technology.

\section{Culture clash}

For the first-time entrepreneur, completing the initial funding round will always be the single most significant event in the development of the company. In theory, the interests of the two parties should be aligned, the focus being the creation of value in the company's equity. Often however, the two sides will have different opinions as to what is important. On the one hand, the founders-especially if they are from academia-will see the money in the bank as a way to concentrate on $\mathrm{R} \& \mathrm{D}$ - to them, the most direct way to add value.

Venture capitalists usually have a different priority. At the top of their list may be installing an experienced senior managermost likely a CEO. If the founders are short of commercial experience, as is often the case, the investor may insist on making this addition. The venture capitalist pictures an organization that combines the drive and technical talent of the founders with the shrewd commercial sense of a seasoned biotechnology or pharmaceutical industry executive. Unfortunately, pursuing this goal often leads to problems.
The focus on finding and retaining experienced managers can lead to problems if it becomes all-consuming, and particularly if it results in the appointment of someone who is not right for the organization. Too often the desire to bring in experienced management results in hiring an individual who may have the perfect profile for a larger company, but does not bring the requisite set of skills for a small and rapidly growing organization.

An experienced manager can bring numerous skills to a a newly formed biotechnology company, such as project planning, establishment of lines of reporting, financial management, remuneration schemes, and identification of markets. These are the sorts of disciplines that give many venture capitalists the feeling that the company is in professional hands. They are also precisely the processes a small company can do without.

\section{What a young company really needs}

The most important need a new company has is to identify where its real opportunities lie. This requires total commitment to bringing early programs to a point where their potential worth can be evaluated in the marketplace. A young biotechnology company cannot do much better than to drive its R\&D forward, continue to stay in touch with potential customers in order to understand their needs, and track what the competition is doing. Speed is of the essence in the early days. The sooner the company can pinpoint where its opportunities lie and bring critical mass to bear in that area, the sooner the company will make commercial progress.

For the entrepreneur, managing a young operation is not too onerous. Formal aspects, such as financial management, can readily be outsourced. By definition, there are not many projects between which to prioritize. The 10-30 or so people who have joined the staff of the company do not need motivating: The natural climate within a small company is as motivating as any working environment can be. The key strategic decisions are mostly scientific: Which technology shows the most potential? Which compound looks the most promising in preclinical studies? A good scientific advisory board, together with a venture capital-dominated supervisory board, can provide all the guidance the entrepreneur 
needs for the first two years. By following this route, precious early money is spent on developing the opportunities set out in the business plan, and the efforts of the organization are not dissipated in looking for an ideal CEO.

\section{Bringing in management from outside}

However, there may come a time when the company really does need management from outside. Either the founder is simply not dealing with important issues, or the company has outgrown his or her ability to manage it. Although the ideal solution is to appoint someone from the founding team who has garnered so much experience that he or she becomes a logical choice for CEO, it is often the case that no-one from inside can lead a larger organization.

Obviously, a decision by the majority shareholders-at this point, probably a consortium of investors - to bring in a CEO from outside against the will of the founders will cause bad feelings. This has potentially damaging effects on the functioning of the organization. The founding manager will almost certainly interpret such a decision by a venture investor as a lack of trust. This step therefore requires careful handling, which is best done by establishing, when the company is founded, expectations for future performance against which the entrepreneurs can be evaluated.

Just as the performance of staff inside the company can be measured annually against pre-agreed goals, so should the board of a startup make it clear to the company's first managers that their ongoing tenure is linked to specific goals. A general statement in the first shareholder's agreement that the venture capitalist reserves the right to change senior management may achieve the desired result, but at the risk of losing the support of the founder. In short, ongoing communication between investor and entrepreneur is critical to easing this difficult transition should the need arise.

\section{Management in Europe versus the US}

For any company, bringing in a new CEO is a momentous step. In Europe, the pool of candidates to fill a position at the top of a biotechnology company is currently very small. A consequence of the relative youth of the industry in Europe is that there simply are not many people with the requisite experience. Those who do have relevant experience, possibly acquired within pharmaceutical companies, are often reluctant to swap the apparent security of a large company for the perceived risk of a biotechnology enterprise. However, current efforts at consolidation in the pharmaceutical industry may help change attitudes toward the risks of biotechnology enterprises.

The European Union notwithstanding, language and cultural differences between European countries and lower mobility, compared with the US, mean that Europe cannot

\section{Case Study: MorphoSys}

Nowhere is increased venture capital activity in biotechnology better evidenced than in Germany. In 1992, there was almost no seed-fund financing available. In spite of this, MorphoSys became the first of a new wave of German biotechnology companies, and has since raised over DM 38 million in equity and soft money. Today, there are at least a dozen venture capital companies that will consider first-round financing for a new German biotechnology enterprise. Part of the attraction for investors is the change in political attitudes toward biotechnology, a tangible consequence of which is plenty of soft money for new enterprises.

The existence of favorable loan and grant schemes in Germany has led to the adoption of a unique mechanism for securing founding finance for a biotechnology company. Several years ago, a federal organization called the Technologie Beteiligungsgesellschaft (TBG) established a scheme by which up to DM 1 million would be provided to a young company in the form of a "silent participation," essentially unsecured debt in which the TBG retained rights to receive information from the company. The most important formal requirement was that an equal sum needed to be committed from a third party in the form of equity. The silent participation bore nominal annual interest repayments, and was repayable after 10 years, with a premium to be paid, the size of which was determined by the success of the company. One of the attractions of the scheme was the simplicity with which the money could be secured, and the lack of bureaucracy involved in administering it.

The success of this scheme prompted the TBG to extend it. Today, amounts up to DM 5 million are available from the TBG on similar terms. Local governments have followed the TBG model in creating their own schemes. In 1996, the state of Bavaria established Bayern Kapital to administer a similar scheme for the benefit of Bavarian companies.

MorphoSys, which was founded in 1992 before the Bayern Kapital or TBG schemes were fully in place, has access to DM 7 million of silent participation. The recently founded Genome Pharmaceuticals Corp. (GPC; Munich) has been able to take full advantage of both schemes, and, with DM 6.5 million in equity, has secured a further DM 10 million through participation of both the TBG and Bayern Kapital.

Through such schemes, founders can sell less of the company than would otherwise be necessary to secure access to capital. This preserves the interests of the entrepreneur and helps to keep valuations in check, since the "silent participations" generally have no equity component. Venture capitalists also gain enormous leverage on their investment. There is even a benefit for the region providing the matching capital: GPC, a spinoff from the Max Planck Institute in Berlin, relocated to Munich to take advantage of the Bavarian scheme, thereby bringing jobs and investment to the region.

be regarded as a single market in the search for industry executives. Germany feels the lack of experienced managers for biotechnology companies as strongly as any European country. The sector is expanding rapidly, and almost all of the requirements for a strong biotechnology industry are in place: outstanding basic science, increasing private investment, a supportive government and access to stock markets designed with growth companies in mind. The only question mark concerns access to the qualified personnel on whom the emerging companies will rely for their success in the longer term.

The extent to which issues of management will hold back development of the biotechnology sector in Germany remains to be seen. The recent departure of Peter Stadler from a senior position within Bayer (Wuppertal) to become a founder of the new biotechnology company Artemis (Tuebingen) indicates that this issue may not be a serious hindrance for much longer.

\section{Conclusions}

There are many examples of startup biotechnology companies that hire experienced man- agers from the pharmaceutical industry only to have to terminate the appointment within a matter of months. Biotechnology and pharmaceutical companies are culturally so different that this should come as no surprise. But the mistake is still being repeated, chiefly by investors who do not appreciate the inherent differences between what a small company needs and what pharmaceutical executives can offer. It should not be forgotten that pharmaceutical firms enter collaborations with biotechnology companies in order to access the speed, flexibility, and creativeness of their R\&D. These are attributes that should be encouraged in a young company, not stifled.

Founding a company with venture capital creates a partnership, and the success of this partnership will go a long way to determining the success of the enterprise. Although the interests of the parties involved should be parallel in terms of maximizing the value of the company's shares, they inevitably have different perceptions of how best to achieve this. Close communication is the best way for the two sides to avoid surprising each other, and to ensure that the relationship works for the benefit of the company. 